\title{
Urgencia de descentralización de pruebas moleculares para el diagnóstico de SARS-Cov-2 en el territorio peruano
}

\section{Decentralization urgency of molecular tests for the diagnosis of SARS-Cov-2 in the Peruvian territory}

Pool Marcos-Carbajal ${ }^{1,2, a}$, Alberto Salazar-Granara, ${ }^{2,3, b}$

\section{Señor editor,}

La nueva enfermedad por SARS-CoV-2 es una amenaza para la salud a nivel global, y se coloca en el tiempo actual, como la pandemia más importante para el ser humano. Con casi de 4 millones de personas contagiadas y 275,000 muertes al 10 de mayo de 2020, superó el coronavirus del síndrome respiratorio agudo severo (SARS-Cov) del $2003^{(1)}$.

El diagnostico SARS-Cov-2 es una piedra angular para la intervención y predicción de la infección humana y es medular eliminar la probabilidad de un resultado falso negativo. El diagnostico se ha realizado en el espectro de la secuenciación genómica-microscopia electrónica (tiempo prolongado), determinación molecular por medio de reacción en cadena de la polimerasa o PCR (tiempo corto) y mediante detección de anticuerpos mediante ELISA o prueba rápida (tiempo corto) ${ }^{(2)}$.

Rápidamente se posiciona a la prueba molecular como la más eficaz, porque tiene la capacidad de detectar el material genético del virus durante todas las fases de la infección humana, con sensibilidad y especificidad de hasta el 99\%; en contraste, pruebas rápidas que detectan anticuerpos presentan sensibilidad y especificidad muy inferior a las pruebas moleculares, y es condicionada a la etapa tardía de la infección humana ${ }^{(3)}$.

En el Perú se realizó un estudio en 144 sujetos hospitalizados con sospecha de infección por SARS-Cov2, a los que se les aplico la prueba molecular y la prueba

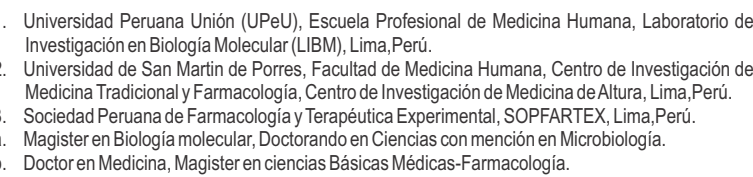
Investigación en Biología Molecular (LIBM), Lima,Perú.

. Universidad de San Martin de Porres, Facultad de Medicina Humana, Centro de Investigación de Medicina Tradicional y Farmacología, Centro de Investigación de Medicina de Altura, Lima,Perú. Sociedad Peruana de Farmacología y Terapéutica Experimental, SOPFARTEX, Lima,Perú. Magister en Biología molecular, Doctorando en Ciencias con mención en Microbiología. Doctor en Medicina, Magister en ciencias Básicas Médicas-Farmacología.

rápida, en este se observó una alta sensibilidad y especificidad de la prueba rápida durante la semana 2 y 3 de la enfermedad, sin embargo, no supero a la prueba molecular que además fue sensible y especifica durante todas las etapas de la infección ${ }^{(4)}$.

En Europa, países como Alemania, Italia, Reino unido y España realizan pruebas moleculares mayores a 30,000 por semana al tener un sistema descentralizado de diagnóstico ${ }^{(5)}$. El método actual de detección en Latinoamérica desde el primer día de inicio de síntomas implica una técnica basada en RT-PCR (real time polymerase chain reaction), que identifica el RNA viral, reportando el valor de $\mathrm{Ct}$ (Ciclo de threshold) permitiendo saber si es positivo un paciente desde el primer día de síntomas y teniendo una relación inversa con las copias del RNA del virus por mililitro de la muestra ${ }^{(6)}$.

En el Perú, el diagnóstico molecular está centralizado en la capital de Lima, y solo se tiene una capacidad para procesar de 700 pruebas por día, en contraste, el virus está presente en 20 regiones diferentes a Lima, y solo 9 regiones tiene la capacidad de procesar las pruebas ${ }^{(7)}$.

Para realizar esta prueba molecular de RT-PCR se requiere un laboratorio con nivel 2 de bioseguridad (procesos de riesgo moderado), insumos de toma de muestra, insumos para extracción de RNA viral, y recurso humano experto en biología molecular ${ }^{(8)}$. Se necesita con urgencia descentralizar y poner en marcha más laboratorios de biología molecular en todo el territorio peruano. El estado peruano a través de CONCYEC realizo un mapeo de que instituciones privadas y universidades cuentan con equipamiento, infraestructura y recurso humano para el diagnóstico molecular de SARS-Cov-2, pero aún no se ha cristalizado en acciones concretas la utilización de los mismos. 
Con este virus circulando en todo el territorio del Perú, nos muestra la posibilidad para la comunidad científica peruana, que es posible iniciar un cambio para la mejora de la salud peruana en cuanto al diagnóstico molecular, no solo para el SARS-CoV-2, sino también de otras enfermedades infecciosas como dengue o tuberculosis.

Por lo tanto, es latente la urgencia de descentralizar pruebas moleculares para el diagnóstico de SARS-CoV-2 en el territorio peruano, porque permitirá un diagnostico real, oportuno, e in situ, esto sumaria directamente a la contención de la infección y a salvar vidas, y también generaría desarrollo e investigación descentralizada para estudios genómicos y de evolución viral.

Conflictos de interés: Los autores niegan conflictos de interés.

Financiamiento: Universidad Peruana Unión y Universidad de San Martín de Porres.

\section{REFERENCIAS BIBLIOGRÁFICAS}

1. Coronavirus disease (COVID-2019) situation reports. [Internet]. [cited 2020 May 10]. Available from: https://www. who.int/docs/defaultsource/coronaviruse/situationreports/20200510covid-19-sitrep111.pdf?sfvrsn=1896976f_2

2. World Health Organization. (2020). Laboratory testing for coronavirus disease 2019 (COVID-19) in suspected human cases: interim guidance, 2 March 2020. World Health Organization. https://apps.who.int/iris/handle/10665/331329

3. $\dot{\bar{N}}$ andini Sethuraman, Sundararaj Stanleyraj Jeremiah. Interpreting Diagnostic Tests for SARSCoV-2. JAMA. 2020 May 6. doi : 10.1001/jama.2020.8259

4. Margot Vidal-Anzardo, Gilmer Solis, Lely Solari, Gabriela Minaya, Beatriz Ayala-Quintanilla, et al. Evaluación en condiciones de campo de una prueba serológica rápida para detección de anticuerpos IgM e IgG contra SARS-CoV-2. Rev Peru Med Exp Salud Publica. 2020;37(2).

5. Aktueller Lage-/Situationsbericht des RKI zu COVID-19; Bereichsmenu. Coronavirus SARS-CoV2; Aktueller Lage ... Archiv. Archiv der Situationsberichte des Robert Koch-Instituts zu COVID-19 (ab 4.3.2020) Weitere Informationen. RKI-Seite zu COVID-19, u.a. mit Hinweisen ... Das Robert Koch-Institut ist ein Bundesinstitut im G e s c h äf t s b e re ich de $s$... https://www.rki.de/DE/Content/InfAZ/N/Neuar tiges_Coronavirus/Situationsberichte/Gesamt.ht $\underline{m}$

6. Ren X, Liu Y, Chen H, Liu W, Guo Z, Zhang Y, et al. Application and optimization of RT-PCR in diagnosis of SARS-CoV-2 infection. medrxiv.org [Internet]. [cited $2020 \mathrm{Apr}$ 26]; Available from: https://doi.org/10.1101/2020.02.25.20027755

7. País a prueba - IDL Reporteros [Internet]. [cited 2020 Apr 26]. Available from: https://idlreporteros.pe/pais-a-prueba/

8. Directrices de Laboratorio para la Detección y Diagnóstico de la Infección con el Nuevo Coronavirus 2019 (2019-nCoV) - OPS/OMS | Organización Panamericana de la Salud [Internet]. [cited 2020 Apr 27]. Available from: https://www.paho.org/es/documentos/directric es-laboratorio-para-deteccion-diagnosticoinfeccion-con-nuevo-coronavirus-2019

\section{Correspondencia}

Pool Marcos Carbajal

Dirección: Laboratorio de Investigación en Biología Molecular (LIBM), Universidad Peruana Unión (UPEU). Carretera central Km 19.5, Ñaña, Lima.

Teléfono: 993328351

Correo: poolmarcos@upeu.pe; pmarcosc@usmp.pe

\section{Revisión de pares}

Recibido: 07/06/2020

Aceptado: $30 / 06 / 2020$ 